\title{
EJERCIENDO PODER POLÍTICO: LOS JUECES Y EL DERECHO ADMINISTRATIVO EN CHILE
}

Beatriz Larraín Martínez*

Recibido: Noviembre 21 de 2013

Aprobado: Marzo 27de 2014

\begin{abstract}
RESUMEN
Este estudio trata sobre la judicialización de la política, o el amplio poder que los jueces chilenos han adquirido en las últimas décadas. Específicamente se centra en algunos aspectos del derecho administrativo, el cual ha crecido gracias a la acción de los tribunales chilenos. Dentro de esta área del derecho examinaremos cómo los tribunales aceptaron competencia para juzgar causas administrativas; la forma en que tratan la responsabilidad del Estado por daños; la forma en que han determinado el plazo de prescripción de los actos administrativos; como ha dirimido conflictos entre la Contraloría General de la República Chilena y otros órganos del Estado y el modo en que aceptan que se impongan las sanciones administrativas. Todo ello para concluir finalmente que los tribunales chilenos enfrentan hoy al poder ejecutivo con un poder que crece y que podría generar conflictos entre estos órganos del Estado en el futuro.
\end{abstract}

Palabras claves: Judicialización, tribunales chilenos, derecho administrativo chileno, poder político, jueces chilenos.

\section{THE EXERCISE OF POLITICAL POWER: JUDGES AND ADMINISTRATIVE LAW IN CHILE}

\footnotetext{
* Profesora de las asignaturas de Introducción al Derecho, Metodología de la Investigación y Sociología Jurídica de la Universidad de Concepción, Chile. Tiene un PhD en "Law, Policy and Society" de la Northeastern University de los EE.UU. Correspondencia a la autora puede dirigirse a blarrain@udec.cl
} 


\begin{abstract}
This study will look at the judicialization of Chilean politics, or the expansion of power of the Chilean judiciary that has taken place over the last few decades. It focuses specifically on administrative law, and the way in which it has grown by virtue of judicial action. Within administrative law we will look specifically at the way in which Chilean judges accepted jurisdiction to judge administrative law cases, how they judge cases of state liability for damages, how they have determined a statute of limitations for administrative acts, how they have resolved conflicts between the General Comptroller and other state organs, and the way in which they accept the imposition of administrative sanctions. We will conclude by stating that the Chilean judiciary is currently facing the executive with an ever rising power, all of which will most certainly cause conflict in the future.
\end{abstract}

Key words: Judicialization, Chilean courts, Chilean administrative law, political power Chilean judges.

\title{
EXERCENDO O PODER POLÍTICO: JUÍZES E DIREITO ADMINISTRATIVO NO CHILE
}

RESUMO

Este estudo trata da criminalização da política, ou o poder amplo que os juízes chilenos adquiriram nas últimas décadas. Especificamente concentra-se em alguns aspectos do direito administrativo, que tem crescido graças à acção dos tribunais chilenos. Dentro desta área de Direito examinará como os tribunais aceitaram a competência para julgar processos administrativos; as formas como eles tratam a responsabilidade do Estado por danos; como eles têm determinado o prazo de prescrição de atos administrativos; como tem resolvido as disputas entre a Controladoria Geral da República do Chile e de outros órgãos do Estado e como eles aceitam que ser impostas sanções administrativas. Tudo isso para finalmente concluir que os tribunais chilenos enfrentam hoje com o poder executivo está crescendo e pode levar a conflitos entre esses órgãos do Estado no futuro.

Palavras chaves: Judicialização, tribunais chilenos, direito administrativo chileno, o poder político, os juízes chilenos. 


\section{INTRODUCCIÓN}

Para comenzar, algunas aclaraciones básicas. En primer lugar cabe preguntarnos ¿de qué hablamos cuando hablamos de poder político de los jueces? En el concepto tradicional de la labor del juez, este es la "boca muerta" a quien sólo toca aplicar la ley que el legislador ha dictado previamente y no le corresponde crear derecho. No tiene rol creativo y su labor es neutra en el sentido de que el juez no debe introducir en la resolución de las controversias sus valores o creencias personales, debiendo decidir estrictamente en función del texto de la ley. Bajo esta noción, aceptar que el juez es un ser humano que tiene valores que lo guían al decidir las causas y que por lo tanto ejerce un rol activo y político, es impensable. Con todo, esta idea clásica no refleja hoy la realidad de la actividad judicial. Desde los trabajos de los realistas norteamericanos de principios de siglo pasado, comienza una escuela de pensamiento que se interesa sobre todo por el estudio de los jueces en cuanto son capaces de tomar decisiones sociales relevantes, y capaces de decidir sobre asuntos de trascendencia social, en otras palabras, capaces de tomar decisiones políticas (Cardozo, 1949; Frank, 1970; Holmes, 1897; Llewelyn, 2000). Mientras la teoría tradicional de la separación de los poderes consideraba que la labor del juez consistía en aplicar la ley al caso concreto a modo de un silogismo, el realismo caracterizó al juez como un verdadero "creador" de norma jurídica. La idea tradicional fue abandonada y criticada por ser una descripción imprecisa de lo que los jueces hacían en la realidad.

Las obras de los realistas generaron nuevas formas de enfocar y estudiar la labor del juez. Entre estos nuevos enfoques se encuentran el prisma del activismo judicial y la judicialización de la política, dos temas que van de la mano. Si bien es cierto se discute qué implica realmente el activismo judicial, en términos simples se puede describir como aquella actitud del juez que trasciende las meras palabras de la ley al decidir un caso si es necesario para proteger los derechos de los individuos. La consecuencia de la labor de jueces activistas es la creación de amplias políticas públicas a través de sus decisiones (Holland, 1991).

1 A más de estos temas, hoy se estudian muchos otros relativos a la actividad del juez con enfoques provenientes de las ciencias sociales, que dejan de lado la mirada típicamente legalista. En Latino América son poco conocidos. Entre ellos, el cómo los valores o actitudes del juez determinan su decisión (Schubert, 1974). Versiones más modernas de esta teoría también existen (Segal \& Spaeth, 2002). La "elección racional" de los jueces y las estrategias que usan al interactuar entre sí para lograr resultados favorables es otro campo de estudio (Epstein \& Knight, 1988). Otras teorías buscan determinar cómo las limitantes institucionales actúan sobre el juez (Clayton \& Gillman, 1999). Igualmente existen estudios sobre la extracción social del juez y como esta influye sobre sus decisiones (Tate, 1981). 
En cuanto a la judicialización, la palabra "judicializar", en términos amplios, significa tratar algo judicialmente, someter una controversia a la decisión de un juez. Luego, el término "judicialización de la política" se refiere a la expansión del poder de los jueces a expensas de los poderes políticos tradicionales, normalmente el parlamento, gabinetes ministeriales, agentes de la administración del Estado (Vallinder, 1995). En otras palabras, en virtud de la judicialización, el juez resuelve asuntos de tipo político-valórico, que según el concepto tradicional de la separación de los poderes y de las teorías democráticas clásicas debieran ser resueltos por quien ha sido elegido para ello, normalmente el parlamento.

Sin duda una de las obras más importantes en este campo es la de Tate y Vallinder (1995), en la cual se entrega una explicación global del tema, al igual que estudios sobre la judicialización de la política en más de una docena de países. Vale la pena analizar brevemente los factores que estos autores identifican como causales del fenómeno, ya que es en este contexto en que los jueces chilenos han expandido su poder y en particular en el área del derecho administrativo. En primer lugar, encontramos la democracia. Ningún régimen dictatorial permitiría la participación de jueces independientes en la resolución de conflictos políticos. La democratización ocurrida durante la década de los noventa en Latino América, África y Asia ha significado la construcción de nuevos órdenes nacionales con órganos judiciales fuertes e independientes, capaces de proteger los derechos humanos.

Otro factor consiste justamente en el impulso a la protección a los derechos personales (Glendon, 1991). La toma de conciencia de que los individuos y las minorías tienen derechos que pueden ser defendidos judicialmente, ha sido crucial. La obligación de los tribunales de proteger estos derechos, aún en contra del deseo de las mayorías, los pone en una posición particularmente favorable para expandir su poder ${ }^{2}$.

El crecimiento de las burocracias estatales, en particular en el área de la administración del Estado ha sido crucial. Este crecimiento, acompañado de una labor cada vez más técnica y compleja que ejercen las agencias del Estado crea mayores oportunidades de conflicto entre la administración y los administrados, e incluso entre las mismas ramas de

2 Este marco teórico discurre sobre la base de lo que llaman en inglés "majority rule" o la regla de mayoría. La traducción al castellano de "majority institution" a "instituciones mayoritarias" debe entenderse en el sentido de institución que se rige acatando la voluntad de las mayorías. Los tribunales de justicia no son órganos mayoritarios ya que en ellos el proceso de toma de decisiones no sigue (necesariamente) la voluntad de la mayoría. Igualmente, no han sido elegidos por una voluntad mayoritaria y por lo tanto no responden ante los electores en elecciones populares. 
la administración. Dentro de este fenómeno se suele dar que las propias instituciones mayoritarias no quieren asumir el costo de tomar decisiones políticas potencialmente conflictivas, particularmente cuando no cuentan con el apoyo de coaliciones gobernantes fuertes. Al no tomar estas decisiones, se produce un vacío de poder que viene a ser llenado justamente por otro poder del Estado, el judicial.

Uno de los puntos más interesantes que destaca la obra de Tate y Vallinder, es que en los países de tradición romanista, en que el juez no debe "crear derecho" sino simplemente "aplicar la ley", es donde se encuentran las instancias más sorprendentes de judicialización. En otras palabras, aún en los sistemas en que las condiciones estructurales no son favorables a ello, ha habido un extraordinario crecimiento del poder de los jueces.

Latinoamérica desde luego no ha quedado ajena a este fenómeno. En efecto, hay quienes estiman que la judicialización de la política es parte de un fenómeno social más amplio de las últimas décadas, cual es la judicialización y juridificación de las relaciones sociales en general que ha tenido lugar en nuestro continente (Sieder, Schjolden \& Angell, 2005).

\section{LASITUACIÓN DE CHILE}

Chile también ha sido testigo del poder que han adquirido los jueces en las últimas décadas. Esta expansión de poder ha sido enorme y ha ocurrido en las más diversas áreas. Este estudio tiene por objeto analizar justamente instancias de poder político de los jueces chilenos, específicamente en el campo del Derecho Público y Administrativo.

En todo el mundo los jueces han contribuido a formar el Derecho Administrativo. Las razones son variadas, según hemos ya apuntado: la creciente complejidad de los poderes ejecutivos, lo que genera mayores posibilidades de entrar en conflicto con las agencias gubernamentales, la existencia de tribunales administrativos independientes de las jurisdicciones ordinarias, y la pérdida de confianza en los gobiernos tecnocráticos ${ }^{3}$.

En el caso de Chile, además existe un factor adicional. Desde el año 1978 existe una herramienta jurídica que ha contribuido a este fenómeno y que ha cambiado totalmente la faz de la litigación, el llamado "recurso de protección" (Soto, 1982). Este recurso, que en verdad es una acción constitucional, fue creado por la Constitución de 1980 y tiene por objeto proteger un catálogo de derechos constitucionales tales como el derecho 
de propiedad, las libertades económicas, el derecho a la vida, entre otros. A través de esta acción, asuntos que jamás habían sido llevados ante los tribunales han sido resueltos por el Poder Judicial chileno. Así, por ejemplo, si debe o no construirse una represa hidroeléctrica en una cierta parte de un río, si es lícito o no que el gobierno distribuya gratuitamente la llamada "píldora del día después", si el gobierno tiene o no derecho a censurar una película, todo tipo de conflictos vecinales, de propiedad, de tala ilegal de bosques, de conflictos con muros medianeros, entre otros. En el campo del Derecho Administrativo, el recurso de protección ha sido clave en esta expansión.

Veamos ahora cómo, y en qué áreas del Derecho Administrativo se ha producido esta expansión del poder de los jueces.

\section{a) Aceptando competencia:}

A comienzos del siglo XX, los tribunales civiles chilenos rechazaban los casos que se presentaban contra la administración. Siguiendo la doctrina común de la época, alegaban que el revisar los actos de la administración significaba invadir el ámbito de otro poder del Estado, a lo cual se negaban. Aún más, una ley del año $1875^{4}$ había prohibido expresamente a los tribunales juzgar causas en contra de la administración.

Cuando se aprobó la Constitución de 1925, los jueces se negaron con mayor razón a decidir casos en contra de la administración ya que esta nueva Constitución estipulaba que estos casos serían resueltos por tribunales contenciosos administrativos que debían ser creados. Sin embargo, pasaron los años y por una serie de razones los anunciados tribunales administrativos no fueron creados (Pantoja, 2005). Por ende, durante décadas los individuos que entraban en conflicto con la administración no tenían donde recurrir ya que los tribunales administrativos anunciados por la Constitución nunca se crearon y los tribunales ordinarios negaban pronunciamiento en estos casos.

En la década de los setenta principia lentamente el cambio. Los jueces comenzaron a hacer sofisticadas distinciones y razonamientos con el objeto de juzgar ciertos actos ilegales de la administración. Sin ningún cambio formal en la normativa ni legal ni constitucional, algunos jueces comenzaron a resolver casos que involucraban la administración. Así, por ejemplo, algunas sentencias establecieron que los tribunales no tenían poder para anular un decreto presidencial ilegal pero sí podían

4 Se trata de la "Ley de Organización y Atribuciones del Poder Judicial". 
dejar un decreto sin efecto cuando este era ilegal ${ }^{5}$. Otra distinción que se hizo a poco andar fue la de los efectos económicos de los actos administrativos ilegales. Nuevamente los tribunales indicaron que no podían anular los decretos ilegales de la administración pero si podían decidir que un individuo debía ser indemnizado por los perjuicios sufridos a causa del decreto ilegal. (Pierry, 2000).

Esta situación cambió radicalmente con la introducción del recurso de protección, que se ha ocupado para impugnar toda clase de actos de la administración. La doctrina chilena en efecto ha indicado que este recurso ha transformado a las cortes de apelación (instancia que conoce del recurso de protección) en verdaderos tribunales administrativos.

\section{b) La responsabilidad del Estado por daños.}

Uno de los tópicos más estudiados y comentados por la doctrina administrativista chilena y donde, a mi parecer, ha habido un avance enorme del poder de los tribunales es en el área de la responsabilidad del Estado (Arteaga, 2007; Huepe, 2006; Marín, 2011; Pierry, 2004). Es además un tópico de creciente interés mediático ya que los montos que los tribunales han asignado han ido creciendo, a la vez que algunos han dicho que en Chile se está transformando en un negocio lucrativo demandar al Estado ${ }^{6}$.

El sistema jurídico chileno reconoce el principio de responsabilidad de todo aquel que cause daño a otro y en particular el artículo 38 de la Constitución lo establece en relación con la administración. Sin embargo, tratándose del Estado como responsable de daño no hay norma legal que establezca derechamente cual es el régimen de responsabilidad aplicable. Luego, el juez tiene dos opciones: aplicar las normas comunes de responsabilidad del Código Civil, en virtud de las cuales el que sufre un daño debe probar que quien lo causó actuó con dolo o culpa, o bien, crear un sistema diverso, que es lo que ha hecho la jurisprudencia chilena ${ }^{7}$ En efecto, los tribunales han construido un sistema de responsabilidad objetiva por daños del Estado ${ }^{8}$. En otras palabras, no es necesario probar culpa, negligencia o dolo por parte del Estado para que este deba indemnizar todo daño que cause.

5 Ver los casos Juez de Melipilla con Presidente de la República, del año 1967 y Juan Bravo Ramos, del año 1972. Ambos casos en Pantoja, 2005, pp. 58-59.

6 El titulo de un artículo publicado en un periódico expresa este punto. Ver Nelson Riffo, "Demandas contra el Estado: ¿Negocio o Derecho?,’ Diario El Sur, Concepción, Chile, Marzo 19, 2007.

7 Un interesante recuento jurisprudencial en Soto, 2009.

8 Cabe notar que no todos los autores están de acuerdo en este punto, y que algunos estiman que no ha habido tal creación de sistema objetivo. Para una exposición de este conflicto ver Enteiche, 2011. 
Esto crea situaciones excepcionales en nuestro sistema ya que altera el régimen de responsabilidad prevalente en Chile, en virtud del cual, para que un sujeto se vea obligado a indemnizar a otro por daño causado, debe probar el dolo o culpa del otro, situación que no sucede cuando el causante del daño es el Estado.

Uno de los casos que inauguró esta postura jurisprudencial fue el de "María Tirado con Municipalidad de la Reina". Una mujer demandó al Estado porque al caer en una fractura del pavimento de la vía pública sufrió lesiones de considerable índole. La sentencia señaló que siendo el Estado responsable del buen estado de las calles, el solo hecho de permitir una situación así le acarreaba responsabilidad, no siendo necesario probar negligencia o dolo.

En otro caso, conocido como "Hexagon Limitada", un importador de automóviles demandó al Servicio de Impuestos Internos Chileno 9 (SII) por daños que este le había causado. Cuando el importador intentó internar vehículos al país, el SII los retuvo, alegando que se debían impuestos al físco. Esto causó demora en el proceso de ventas provocando grandes pérdidas para la empresa. El juez ordenó al fisco indemnizar al importador, y declaró expresamente que las normas de responsabilidad establecidas en el Código Civil (que establecen la obligación de probar el dolo o culpa) no eran aplicables al Estado. No daban los jueces en este caso razones para esta afirmación tan amplia.

En el reciente caso "Torres Velásquez y otros con Servicio de Salud de Talcahuano", la Corte de Apelaciones de Concepción sostuvo que "basta, por tanto, la causalidad material como factor de atribución de responsabilidad", no siendo necesaria la prueba del dolo o culpa. Múltiples casos contienen esta misma solución ${ }^{10}$.

Cabe notar que estos fallos contienen muchísimos argumentos doctrinales, legales y exegéticos para justificar por qué el sistema aplicable al Estado es el de responsabilidad objetiva. Sin embargo, no descienden al análisis de razones de políticas públicas, o de conveniencia social por las cuales deba alterarse el régimen normal aplicable en la materia.

9 Agencia administrativa encargada de la recaudación de impuestos chilenos.

10 Villegas Lorca v. Municipalidad de Providencia, 90 Revista de Derecho y Jurisprudencia, 226 (2 $2^{\mathrm{a}}$ parte, sección 5, 1993); SAG, 162 Gaceta Jurídica, 58 (1993); Rodríguez Guaita v. SAG, 173 Gaceta Jurídica, 95 (1994); Aja García v. Municipalidad de Talcahuano, 96 Revista de Derecho y Jurisprudencia, 59 (2ª parte, sección 5, 1999); Cáceres Miriam v. Municipalidad de Concepción, Lexis Nexis número identificador 32961 (rol 1018-2005); Villarroel Guerrero v. Municipalidad de Valparaíso, Lexis Nexis número identificador 33021 (rol342-2005). 
Evidentemente que adoptar uno u otro sistema de responsabilidad por los daños causados por el Estado tiene consecuencias importantes. En primer lugar, con respecto al individuo que demanda al Estado, se crea una ventaja enorme ya que un sistema de responsabilidad objetiva, que no requiere probar más que el daño es altamente beneficioso pues libera de la pesada carga de la prueba.

Mirado desde otro punto de vista, y en segundo lugar, esto genera un problema de trato desigual. El Estado es un ente abstracto y quienes actúan a su nombre son individuos. Con este sistema las personas están sometidas a una medida distinta según si actúan como particulares o si actúan como agentes del Estado. En un caso si actúan como individuos se les aplican unas reglas y si actúan como agentes del Estado otra, siendo que las personas naturales serán las mismas.

En tercer lugar, y como contrapartida del primer punto, este sistema es evidentemente perjudicial para el Estado ya que significa un mayor deber de cuidado que el de un particular, con la correspondiente elevación de los costos. Como destaca Aldunate (2000) estos costos podrían llegar a ser tan elevados que el Estado deje de ejecutar ciertos actos o traspase estos costos directamente a los ciudadanos vía aumento de impuestos.

Apunta además a una cuarta consecuencia. Si obligamos al Estado a responder de todos los daños, incluso de los daños derivados de actos lícitos, estamos cambiando la noción misma de Estado, al punto de eliminar la razón misma por la cual tenemos Estado. Si hacemos que el Estado responda por todo daño, eliminamos la posibilidad de articular un interés común que justifique el deber de los particulares de soportar una cierta cantidad de daños como una obligación en pos del bien común. Este concepto de Estado lo reduce a un simple coordinador o intermediario de intereses privados y se transforma en un redistribuidor de ingresos ya que cada vez que causa daño debe pagarlos con dinero ajeno (el de los contribuyentes).

El mero hecho de que los tribunales tengan la facultad para establecer la norma en virtud de la cual será juzgado el Estado trae importantes consecuencias ya que implica que el juez tiene poder político para decidir cómo debe el Estado distribuir sus recursos. Una decisión judicial que lo condena a pagar una indemnización en dinero es una decisión política y financiera ya que distribuye recursos públicos. 
A pesar de este criterio tan estricto que los tribunales han aplicado para resolver las demandas en contra del Estado, han recurrido a un criterio absolutamente distinto cuando se trata de daños causados por el mismo Poder Judicial como poder del Estado y no por la administración. La Constitución Política de Chile establece normas especiales con respecto a los daños causados por una decisión judicial, señalando que en caso de una condena injustificadamente errónea o arbitraria, el afectado puede demandar al Estado para que le repare el daño causado ${ }^{11}$. Sin embargo, el modo en que la Corte Suprema ha interpretado estas normas ha sido tan estricto, que son muy pocos los casos en que efectivamente se llega a otorgar indemnización. En efecto, la interpretación que la Corte Suprema ha dado a estas normas excede con creces la letra de la ley estableciendo un estándar tan estricto que para que un individuo obtenga indemnización por error judicial tendría que haber sido condenado por un juez "mentalmente insano" (González, 2004). Sólo una decisión tan extremadamente irracional parece adecuada para que la Corte Suprema chilena declare el derecho a cobrar indemnización. Un estudio en la materia reveló que de las sentencias publicadas en las principales revistas jurídicas chilenas, sólo el $9 \%$ son declaradas erróneas o arbitrarias y dan lugar a indemnización de perjuicios (Carmona, 2001). Otro autor habla incluso de la "agónica existencia" de la acción de indemnización por error judicial, ya que en la práctica esta es una ilusión y no una realidad (Cárcamo, 2012).

Un caso ilustrativo en la materia fue el conocido como el caso "La Calchona". La petición de indemnización fue rechazada por la Corte Suprema, razón por la cual fue llevada a la Comisión Interamericana (CI), con miras a ser presentada posteriormente ante la Corte Interamericana de Derechos Humanos (CIDH). El caso involucraba a tres hombres que habían sido erróneamente condenados por un delito y que estuvieron encarcelados por más de 5 años. La sentencia judicial que los había condenado se había basado para ello únicamente en confesiones ilegalmente obtenidas por la policía. Cuando la evidencia biológica (análisis de ADN) finalmente exoneró a los hombres de culpa, recurrieron ante los tribunales chilenos en busca de indemnización por los perjuicios sufridos. La Corte Suprema Chilena, determinó que no había encarcelamiento erróneo ni injusticia que ameritara indemnización por error judicial a pesar de los múltiples errores e irregularidades en que había incurrido el juez. Ante esta negativa los afectados recurrieron a la instancia internacional, llevando su caso ante

11 Cabe destacar que la indemnización por error judicial sólo procede en casos criminales y no procede en casos civiles. 
la CI. Sin embargo, el caso no llegó a ser conocido por la Comisión puesto que el gobierno chileno rápidamente decidió negociar con los afectados y llegar a un acuerdo antes de llegar a una resolución formal por parte de la Comisión (Carocca, 2002). El expedito acuerdo extrajudicial a que arribó el Estado con los peticionarios sugiere, sin duda, que el gobierno chileno tenía conciencia de que la legislación y prácticas de la Corte Suprema no se adherían a los estándares internacionales y deseaba evitar una declaración formal en ese sentido. En efecto, la Convención Interamericana de Derechos Humanos establece en su artículo 10 una norma mucho más amplia que la establecida por la Constitución chilena para obtener indemnización por error judicial.

Este "doble estándar" del Poder Judicial de aplicar una medida tan benevolente cuando la decisión de uno de sus miembros es cuestionada, y de ser extremadamente estricto con la administración del Estado, apoya la tesis de quienes han indicado que la judicatura chilena hace uso de su poder sobre todo cuando sus intereses corporativos están en juego (Peña, 2004). Sin lugar a dudas que esto es una certera muestra de poder político.

\section{c) El plazo de prescripción para anular los actos de la administración:}

En términos generales, la legislación chilena a la fecha no regula expresa y cabalmente la nulidad de los actos de la administración del Estado o de los actos de Derecho Público. Siguiendo la tradición de los países del derecho romanista, se regula sí extensamente el tema de la nulidad de los actos de los particulares en el Código Civil. El año 2003 se dicta la ley de bases de los procedimientos administrativos, Ley número 19.880 que viene a llenar parcialmente un vacío en el tema. Sin embargo, han sido la doctrina y la jurisprudencia las que han moldeado principalmente esta área del derecho (Bermúdez, 2010).

En relación con los plazos de prescripción, en Chile (como en la mayoría de los sistemas jurídicos) todas las acciones tienen un plazo de prescripción, o de caducidad, en otras palabras, un plazo máximo dentro del cual deben ejercerse. En el caso de acciones que buscan anular actos ilegales de la administración, no existe una regulación legal expresa en la materia, es decir, no existe plazo claro dentro del cual se deba ejercer la acción de nulidad de Derecho Público. El problema con que se enfrentan, por lo tanto, los jueces es el de determinar si el plazo general 
de prescripción contenido en el Código Civil para los actos de los particulares (normalmente aplicado a los casos en que no existe regulación como norma residual) debe ser aplicado a los actos ilegales de la administración. Esto significaría dar un plazo de 4 o 5 años dentro del cual debe ser ejercida la acción. La otra alternativa es considerar que las normas del Código Civil no se aplican en este caso, lo cual significaría que no hay plazo de prescripción y las acciones puedan presentarse ante los tribunales en cualquier momento.

Un caso que marcó un hito en esta materia fue "Aedo vs. Fisco" del año 2002, en el cual la Corte Suprema indicó que no hay plazo de prescripción para impugnar un acto administrativo por ilegal. Un acto ilegal, razonó la Corte, es un acto que no tiene valor, porque transgrede el orden constitucional y el Estado de derecho. Por lo tanto, un juez puede en cualquier momento declarar un acto de la administración ilegal, porque al hacerlo está meramente afirmando el principio de que "la administración debe someterse a la Constitución y la Ley". Muchos otros casos contemplaron esta misma solución (Soto, 2009).

Sin embargo, luego la jurisprudencia de la Corte Suprema haría una distinción importante. Seguiría sosteniendo que el ejercicio de la acción para obtener la declaración de nulidad de un acto es imprescriptible pero pasa a distinguir la situación en que se ejerce la acción tendente a obtener una compensación monetaria por los daños causados por el acto. En este caso sí se aplicarían las normas del Código Civil sobre la prescripción (Pfeffer, 2005) y, por ende, en este caso habría excepcionalmente plazo de prescripción. La regla general, sin embargo, seguiría siendo la imprescriptibilidad para los actos nulos.

\section{d) Las decisiones del Contralor y el Poder Judicial:}

La Contraloría General de la República es un organismo público e independiente, el cual debe, por mandato constitucional y legal, controlar la legalidad de los actos de la administración. También fiscaliza los gastos del gobierno, lleva la contabilidad general de la nación, y evalúa y aplica sanciones a los funcionarios públicos. El Contralor General, que está a cargo de este organismo es nombrado por el Presidente de la Republica con el acuerdo mínimo de las $3 / 5$ partes del Senado.

La situación actual de la Contraloría frente al poder de los jueces es la de una función "degradada" (Pierry, 2000), ya que sus decisiones están sujetas permanentemente a revisión por los tribunales por medio del 
recurso de protección. Esta situación ha llegado a afectar la esencia de la labor de la Contraloría de modo que, en su opinión, esta debiera redefinir de su rol.

En efecto, por vía del recurso de protección los tribunales han ordenado a la Contraloría abstenerse de ciertas actuaciones, invalidando sus resoluciones, y le han obligado a adoptar decisiones contrarias a sus políticas. Esto ha llevado a la Contraloría a plantear sus reclamos en varias ocasiones frente al Senado, órgano que de acuerdo con la Constitución tiene el poder de decidir las disputas que se den entre órganos del Estado.

Uno de tales casos involucraba a la Compañía de Teléfonos Chilena (CTC), la Secretaría de Transportes y Telecomunicaciones (órgano de la administración del Estado), y la Contraloría. La CTC presentó un recurso de protección en contra de la Contraloría porque esta había autorizado un decreto expedido por la Secretaría de Transportes y Telecomunicaciones, que CTC estimaba ilegal. La Corte de Apelaciones de Santiago ordenó al Contralor revisar y anular su decreto. El Contralor se negó argumentando que la Corte no tenía poder para revisar sus decisiones y le solicitó al Senado que invalidara la decisión de la Corte. El Senado dictaminó que el recurso de protección no podía ser utilizado para invalidar actos de la Contraloría. Usando argumentos de texto legal, el Senado señaló que la Contraloría y el Poder Judicial son órganos constitucionales separados, cada uno con un rol distinto. La Contraloría está a cargo de revisar la legalidad de los actos de la administración y dar a los jueces el derecho de revisar dicha función significaría darle el derecho a ejecutar una función que la Constitución encomendó a la Contraloría y no a los jueces. Esto violaría el principio de la especificidad de las funciones de los órganos públicos, razonó el Senado ${ }^{12}$.

Sin embargo, y a pesar de lo amplia y categórica que aparece esta afirmación, los tribunales han entendido que las decisiones del Senado sólo son válidas para el caso específico en que se dictan. Por lo tanto, cada vez que un tribunal acepta jurisdicción en un nuevo recurso de protección presentado en contra de la Contraloría, el Contralor deberá recurrir nuevamente al Senado para que este declare que el tribunal no tiene jurisdicción para juzgar sus actos, si lo estima necesario. A pesar de que el Senado ha fallado a favor de la Contraloría en casi todos los casos

12 Informe de la Comisión de Constitución, Legislación y Justicia del Senado de Chile, de 28 de Julio de 1994. Ver Aylwin, 2000. 
que se le han presentado, las Cortes de Apelaciones han continuado decidiendo casos en contra de la Contraloría. En otras palabras, los tribunales no han seguido la opinión del Congreso en la materia, siguiendo su propia doctrina en virtud de la cual tiene plenos poderes para revisar los actos de la Contraloría.

\section{e) Las sanciones administrativas:}

Todos los órganos administrativos tales como servicios públicos, ministerios, o municipalidades, pueden imponer sus sanciones a los funcionarios que no cumplen con las normas establecidas en la ley e incurren en faltas administrativas. Para hacer esto, el órgano público debe normalmente, en primer lugar, llevar a cabo una investigación administrativa, en la cual se establecerán los hechos que serán la base para la aplicación de una sanción. Con el resultado de la investigación, la administración puede imponer una variedad de acciones disciplinarias, desde la suspensión hasta la remoción del funcionario de su cargo. La ley establece normas procedimentales muy específicas para que se lleven a cabo estas investigaciones.

El caso típico en la materia es que la administración, luego de una investigación sumaria, aplica una sanción al individuo. Tras ello, este suele recurrir a los tribunales para que dicha sanción sea revocada, normalmente invocando que ha sido privado de su derecho de propiedad sobre su cargo, en caso de que se aplique la sanción de remoción del cargo $^{13}$. El conflicto se suscita cuando el tribunal decide a favor del peticionario, ya que en esta situación la administración pierde la posibilidad de regular y sancionar la mala conducta de los funcionarios públicos. Así la administración se ve impedida de remover individuos de sus cargos, haciendo la imposición de sanciones una labor muy compleja. El manejo del personal de la administración se convierte en una actividad continuamente sujeta a la posibilidad de decisión judicial contraria a las medidas adoptadas.

Aún más, esto deja a los funcionarios públicos en una posición muy distinta y aventajada en relación con los trabajadores del sector privado. Los tribunales no han permitido, por regla general, la interposición de recursos de protección cuando individuos del sector privado han invocado derecho de propiedad sobre su puesto de trabajo cuando han sido despedidos de él. Claramente la protección que los tribunales

13 Así, por ejemplo, en causas Corte Suprema Recurso de Protección, rol 8-98, en 215 Gaceta Jurídica, 36; causa Corte Suprema Recurso de Protección, rol 2326-97, y Corte Suprema, Recurso de Protección, rol 479-93. 
otorgan no es la misma para trabajadores del sector privado y para funcionarios públicos.

Un tal caso involucraba a una profesora de enseñanza básica que había postulado a un trabajo en una escuela del Municipio ${ }^{14}$. El cargo al que había postulado requería, por ley, ser asignado en virtud de concurso público para el cual las partes interesadas debían presentar su curriculum vitae para evaluación. La mujer ganó el concurso y fue designada en el cargo. Sin embargo, un par de días después de ser notificada del resultado, la Municipalidad anuló el concurso alegando que se había incurrido en errores procedimentales, dejando sin efecto la designación de la mujer en el cargo. La afectada recurrió a los tribunales, alegando que cuando había sido notificada de los resultados del concurso y designada en el cargo, había adquirido un derecho de propiedad sobre ese cargo. Al anular la Municipalidad el decreto, ella había sido privada de su derecho de propiedad. La Corte falló en su favor, y declaró que en efecto había sido privada de su derecho de propiedad y ordenó a la municipalidad restablecer el decreto y otorgarle el cargo de profesora que se le había asignado originalmente vía concurso público.

Siguiendo esta misma línea, la jurisprudencia ha llegado a fallar a favor de un funcionario público cuando ha sido cambiado de cargo. En un caso, un funcionario municipal alegó que había sido ilegalmente reasignado en sus funciones ${ }^{15}$. Tras años de desempeñarse como director de un departamento municipal, y en virtud de un decreto, había sido removido de ese puesto y ubicado en otro, dentro de la misma municipalidad, con el mismo sueldo, pero con funciones indeterminadas. Alegó ante la Corte que estaba siendo privado de su trabajo como director, trabajo que él estimaba como parte de su propiedad. El tribunal falló en su favor, y ordenó a la municipalidad reinstalar al trabajador en su cargo previo como director. Cambiarlo de puesto había significado afectar su derecho de propiedad, en opinión de la Corte.

\section{f) Hacia nuevos tribunales administrativos:}

Para concluir cabe examinar un último punto. El año 2003 la Ley $19.886^{16}$ creó el primer tribunal administrativo chileno, el Tribunal de

14 Causa rol número 235-94, 27 de abril de1995, Recurso de Protección, Corte de Apelaciones de Concepción.

15 Causa rol número 152-96 y 153-96, 30 de Agosto de, 1996, Recurso de Protección, Corte de Apelaciones de Concepción.

16 Ley 19.886 de 30 de Julio de 2003, llamada "Ley de Bases sobre Contratos Administrativos de Suministro y Prestación de Servicios." 
Contratación Pública. Este no es un tribunal administrativo completo ya que tiene jurisdicción limitada. Fue creado para resolver problemas que deriven de casos de procedimientos administrativos ilegales o arbitrarios a que haya lugar en los procedimientos para asignar contratos públicos. En caso que el individuo que contrate con el Estado considere que la administración ha procedido ilegal o arbitrariamente en tal proceso, puede presentar una acción especial frente a este tribunal.

Vale la pena anotar que el mensaje o moción presidencial que presentó el proyecto de ley ante el Congreso establecía una integración muy específica del mismo tribunal: un miembro debía ser designado por el Presidente de la República, y otro por el Ministro de Hacienda. Estos miembros debían ser elegidos de entre una lista propuesta por la Cámara de Comercio Chilena. Un tercer miembro seria un juez de la Corte de Apelaciones de Santiago elegido por sorteo. Sin embargo, cuando la ley fue discutida en el Congreso, este le cambió la composición al Tribunal, y hoy son todos elegidos por los miembros del Poder Judicial.

Cabe reflexionar sobre las intenciones del Ejecutivo al crear este tribunal y más aún sobre la composición que proponía. Según lo hemos visto, cuando los jueces deciden casos en contra de la administración del Estado, esta normalmente se ve dañada, menoscabada en sus poderes. La creación de este tribunal puede ser vista como un esfuerzo de parte de la administración por recobrar algo del control en estos asuntos, especialmente designando a los miembros del tribunal y dándole poder para decidir un aspecto tan sensible económicamente como la relación contractual del Estado con los particulares.

Es más, el texto de la norma, al describir las acciones que los individuos pueden intentar en contra de la administracion y presentar ante el tribunal, es casi idéntico al texto de la Constitución que describe el recurso de protección. Esto parecería sugerir que la intención del Ejecutivo hubiera sido trasladar el recurso de protección a otro tribunal que de algún modo se pudiera controlar y no dejarlo todo en manos de un Poder Judicial impredecible.

En efecto, ha habido algunos casos importantes que han recibido cobertura mediática por los grandes montos de dinero involucrados. Uno de ellos fue el de la empresa Siemens S.A., que demandó al Registro Civil Chileno en el proceso de licitación de las cedulas de identidad y pasaportes. El Registro Civil dejó fuera a Siemens S.A., del proceso, alegando que la empresa no había adjuntado todos los documentos que se 
requerían para ello. Siemens S.A., alegó ante el Tribunal de Contratación Pública que el Registro Civil había incurrido en ilegalidad y arbitrariedad, cosa que el Tribunal estimó que no era efectivo ${ }^{17}$.

\section{CONCLUSIONES}

La complejidad de los asuntos que la administración decide, junto con la democracia chilena, que ha permitido a los individuos libremente llevar sus disputas con la administración ante los tribunales, junto a la actitud de los jueces chilenos frente a la administración, han configurado un escenario propicio para la expansión del poder de los jueces. En efecto, el Poder Judicial chileno ha cambiado su actitud hacia la administración del Estado durante los últimos 30 años. No sólo ha creado derecho, derribando el mito de que los jueces no crean derecho, sino que también ha impuesto su autoridad ante el Poder Ejecutivo.

Políticamente pudiera parecer que es un error permitir que los tribunales intervengan en estos asuntos ya que significa intrusión en los actos discrecionales de la administración, poniendo así a la administración en una situación de subordinación en relación con el Poder Judicial y afectando el balance constitucional de los poderes.

En efecto, en todos los casos planteados en este estudio resulta "dañada" de algún modo la administración, ya sea permitiendo la presentación de acciones sin límite de prescripción, como fijándole un estándar más alto en caso de indemnización de daños, permitiendo la revisión judicial de los actos de la Contraloría a pesar de oposición del Senado, y estableciendo un estándar más alto para la administración como empleador. Esta expansión de poder también ha creado desigualdades profundas, según vimos. En caso de las sanciones administrativas la interpretación amplia dada al derecho de propiedad ha permitido que los funcionarios públicos aleguen tener un derecho de propiedad sobre su cargo, siendo que a los trabajadores del sector privado no les ha sido otorgado tal derecho por la jurisprudencia. El sujetar a la administración al sistema de responsabilidad objetiva contrasta con el modo en que la Corte Suprema ha considerado la responsabilidad del propio Poder Judicial para responder en caso de error.

Es interesante notar que la literatura en el tema cita la existencia de tribunales administrativos como un factor esencial en el crecimiento del derecho administrativo vía jurisprudencia (Shapiro \& Stone, 1994). 
Chile, siendo uno de los pocos países de la tradición jurídica romanista que no tiene tribunales administrativos independientes, sería una excepción a esta regla. Pese a la ausencia de tribunales administrativos independientes, los jueces chilenos han hecho crecer el derecho administrativo del modo que hemos visto.

Habrá que observar la jurisprudencia del nuevo Tribunal de Contratación Pública para ver de qué modo sigue o se modifica esta tendencia.

\section{REFERENCIAS BIBLIOGRÁFICAS}

Aldunate, Eduardo. (2000). Consecuencias Constitucionales de la Doctrina sobre Responsabilidad Objetiva del Estado. Revista de Derecho del Consejo de Defensa del Estado, (2), 61.

Arteaga, Ignacio. (2007). La responsabilidad extracontractual de la administración del Estado por el daño antijurídico: acercando posiciones. Gaceta Jurídica, (329), 23.

Aylwin, Arturo. (2000). Notas Ilustrativas para el Estudio de la Función Fiscalizadora de la Contraloría General de la República y el Poder Judicial. Revista de Derecho del Consejo de Defensa del Estado, (2), 13.

Bermúdez, Jorge. (2010). Estado Actual del Control de Legalidad de los Actos Administrativos. ¿Qué queda de la Nulidad de Derecho Público? Revista de Derecho, Universidad Austral de Chile,(23), 103.

Carcamo, Alejandro. (2012). Análisis de la Situación Actual de la Responsabilidad del Estado Juez en Chile: ¿Una Ficción o una Realidad? Gaceta Jurídica, (381), 7.

Cardozo, Benjamin. (1949). The Nature of the Judicial Process. New Haven: Yale University Press.

Carmona, Carlos. (2001). La Responsabilidad del Estado-Juez: Revisión y Proyecciones. Revista de Derecho Público, (66), 307.

Carocca, Alex. (2002). Reflexiones Sobre el Derecho a la Reparación del Error Judicial en Chile a Propósito de la Solución Amistosa ante la Comisión Interamericana de Derechos Humanos en el llamado Caso del Puente la Calchona. Ius et Praxis, (8), 641. 
Chile. Corte de Apelaciones de Concepción. 2003. Torres Velásquez y otros con Servicio de Salud de Talcahuano. Causa rol 1703.

Chile. Corte Suprema de Justicia. 1982. Tirado v. Municipalidad de la Reina, 78 Revista de Derecho y Jurisprudencia, 35 (segunda parte, sección 5).

Chile. Corte Suprema de Justicia. 1984. Hexagon Limitada Sociedad Importadora y Exportadora v. Fisco, 81 Revista de Derecho y Jurisprudencia, 217 (segunda parte, sección 5).

Chile. Corte Suprema de Justicia. Junio, 1996. La Calchona. Causa rol $32.099,27$.

Chile. Corte Suprema de Justicia. Noviembre 2000. Aedo v. Fisco. Causa rol 852-00, 27.

Clayton, Cornell \& Howard, G. (Eds). (1999). Supreme Court Decision Making: New Institutionalist Approaches. Chicago. University of Chicago Press.

Enteiche, Nicolás. (2011). El Fundamento de la Responsabilidad Extracontractual del Estado Administrador en Chile: Revisión de la Evolución Jurisprudencial (1999 - 2010). Actualidad Jurídica, (23), 109.

Epstein, L., \& Jack, K. (1998). The Choices Justices Make. Washington DC: Congressional Quarterly Press.

Frank, Jerome. (1970). Law and the Modern Mind. 6th edition. Gloucester, Mass: Peter Smith.

Glendon, Mary Ann. (1991). Rights Talk: The Impoverishment of Political Discourse. New York: The Free Press.

Holland, Kenneth. (Ed). (1991). Judicial Activism in Comparative Perspective. New York: St. Martin's Press.

Holmes, Oliver W. (1897). The Path of the Law. Bedford, MA: Applewood Books.

Huepe, Fabián. (2006). Responsabilidad del Estado, Falta de Servicio y Responsabilidad Objetiva en su Actividad Administrativa, Santiago, Editorial Lexis Nexis. 
Kloss, Soto E. (2009). Lo que dice la Jurisprudencia de la Corte Suprema Respecto de la Nulidad de Derecho Público de los Actos Administrativos. Ius Publicum, (23), 87-106.

Lafon, Lucienne. En C. Neal, T., \& Torbjorn, V. (eds). (1995). The Global Expansion of Judicial Power. New York: New York University Press.

Llewelyn, Karl. (1930). A Realistic Jurisprudence; the Next Step. Columbia Law Review, (30), 431.

Marín, Urbano. (2011). Aspectos de la Falta de Servicio como Fuente de la Responsabilidad Estatal. Revista de Derecho del Consejo de Defensa del Estado, (25), 21.

Pantoja, Rolando. (2005). La Inexplicable Ausencia de una Justicia Administrativa en el Estado de Chile. Revista de Derecho del Consejo de Defensa del Estado,(13), 27.

Peña, Carlos. (1994). Hacia una Caracterización del Ethos Legal: de Nuevo sobre la Cultura Jurídica. En Agustín Squella. (ed), Evolución de la Cultura Jurídica Chilena. Santiago: Corporación de Promoción Universitaria.

Pfeffer, Emilio. (2005). La nulidad de Derecho Público: Tendencias Jurisprudenciales. Revista de Derecho Público,(67), 29.

Pierry, Pedro. (2000). Tribunales Contencioso - Administrativos. Revista de Derecho del Consejo de Defensa del Estado,(1), 1.

Pierry, Pedro. (2004). ¿Es objetiva la Responsabilidad del Estado? Estado Actual de la Jurisprudencia. Revista de Derecho del Consejo de Defensa del Estado, (11), 11.

Schubert, Glendon. (1974). The Judicial Mind Revisited. New York: Oxford University Press.

Segal, J,. \& Harold, S. (2002). The Supreme Court and the Attitudinal Model: Revisited. New York: Cambridge University Press.

Shapiro, M., \& Stone, A. (1994). The New Constitutional Politics of Europe. Comparative Political Studies, (26), 397. 
Sieder, R., Schjolden, L., \& Angell, A. (Eds). (2005). The Judicialization of Politics in Latin America. New York: Palgrave Macmillan.

Soto, Eduardo. (2009). Responsabilidad del Estado por Daños de su Administración. Algunos casos de Jurisprudencia. Ius Publicum, (22), 91.

Soto, Eduardo (1982). El Recurso de Protección: Orígenes, Doctrina y Jurisprudencia. Santiago. Editorial Jurídica de Chile.

Soto, Eduado (2009). Lo que dice la jurisprudencia de la Corte Suprema Respecto de la Nulidad de Deercho Público de los Actos Administrativos. Ius Publicum, (23), 87.

Tate, C. N., \& Torbjorn, V. (Eds). (1995). The Global Expansion of Judicial Power. New York: New York University Press.

Tate, C. Neal. (1981). Personal Attribute Models of Voting Behavior of US Supreme Court Justices: Liberalism in Civil Liberties and Economic Decisions 1946-1978. American Political Science Review, (75), 355. 